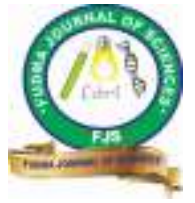

FUDMA Journal of Sciences (FJS)

ISSN online: $2616-1370$

ISSN print: 2645 - 2944

Vol. 4 No. 2, June, 2020, pp 414 - 419

DOI: https://doi.org/10.33003/fjs-2020-0402-153

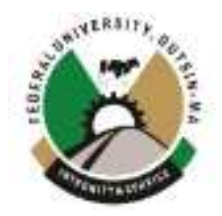

\title{
DENSITY OF MOSQUITO SPECIES AND EFFECT OF SOME CLIMATIC PARAMETER IN AMINU KANO TEACHING HOSPITAL, KANO, NIGERIA
}

\author{
${ }^{1}$ Haruna, A., ${ }^{1}$ Yayo, A. M., ${ }^{1}$ Mohammed, Y., ${ }^{* 1}$ Idris, A. M., ${ }^{1}$ Takalmawa, H. U., ${ }^{2}$ Aliyu, A. A., ${ }^{3}$ Umar, A. A., ${ }^{3}$ Tsiga- \\ Ahmed, F. I. \\ ${ }^{1}$ Department of Medical Microbiology and Parasitology, Faculty of Clinical Sciences, College of Health Sciences, Bayero \\ University, Kano \\ ${ }^{2}$ Department of Zoology, Federal University Lafia, Nasarawa State, Nigeria. \\ ${ }^{3}$ Departemt of Community Medicine, Faculty of Clinical Science, College of Health Science, Bayero University, Kano, Nigeria \\ *Corresponding Author's email: amikibiya@gmail.com; +2347038228730.
}

\begin{abstract}
There is a paucity of information on the species of mosquito in Kano City Northern Nigeria. Numerous mosquito control programs that had taken place in Kano State and its environs, mosquitoes remain a problem in the state; therefore a study was undertaken to the relationship between density ofmosquito species and the effect of some climatic parameters on the mosquito distribution in Aminu Kano Teaching Hospital, Kano, Nigeria. The mosquito species were collected using the CDC light trap method and climatic parameters such as temperature and relative humidity were recorded at every one hour of the experiments. A total of 26,652 mosquitoes were collected from January to July 2018. Out of the 26,652, $17444(65.46 \%)$ were Culex speciesand 9208 (34.54\%) were Anopheles mosquitoes. Culex species were observed to peak between 10:00 - 11:00 pm (5435) while Anopheles mosquito species were observed to attain their first peak at 3:00 - 4:00 am (3416). High collections of mosquitoes were obtained at $27.10^{\circ} \mathrm{C}$ and relative humidity of $69.7 \%$ and $68.60 \%$ for Culicine and Anopheline mosquitoes respectively. This study provided information on the mosquito species diversity in respect to seasonal and periodic variation at AKTH and the effect of some climatic parameters.
\end{abstract}

Keywords: Anopheles species, Culex species, Population, Temperature, Relative Humidity.

\section{INTRODUCTION}

Mosquitoes are vectors of protozoan, nematodes, viruses, and parasites, causing infections such as yellow fever, dengue hemorrhagic fever, malaria, filariasis, and several forms of encephalitis (WHO, 2017). The disease transmitted by species of mosquitoes continues to cause morbidity and mortality in humans, domestic animals, and wildlife.

In Nigeria mosquito-borne diseases particularly malaria and some emerging and re-emerging infections such as Zika, dengue fever, yellow fever, constitute a big threat to public health. However, there is paucity of information on the species of mosquito in Kano City Northern Nigeria. Despite mosquito control programs that had taken place in this state and its environs, mosquitoes remain a problem in the state and there is little information on the relationship between mosquito species abundance and the effect of some climatic parameters on the mosquito distribution in the study area, Kano State.

Climatic changes were reported by several researchers, to have direct affect on the distribution of mosquito population (Ayanda et al., 2009). Climatic factors like temperature, rainfall and relative humidity most be conducive for the survival of the mosquito (Herekar et al., 2020). Tropical countries, including
Nigeria have the optimal climatic condition for the survival of mosquitoes (Ayanda et a., 2009; Manyi et al., 2015). In a study done by Manyi et al. (2015) in North Central Nigeria they reported that mosquitoes population were found to be more abundance at optimal temperature of $29.5^{\circ} \mathrm{C}-38.2^{\circ} \mathrm{C}$ and relative humidity of $44 \%-86 \%$ (Manyi et al., 2015).

The collection of mosquitoes landing on human bait is considered the most direct and reliable method for determining human-biting activity since female mosquitoes are collected as they attempt to feed on human collectors (Jiang et al., 2007). Human landing collection (HLC) is often considered as the sole standard in research study for estimating mosquito human contact, but its use is slowly declining due to ethical concerns, potential exposure of collectors to mosquito-borne pathogens, medical and legal considerations (Wong et al., 2013; Lima et al., 2014).

Transmitted estimate, based on the prevalence or density of human infection is susceptible to microheterogeneity caused by climatic factors and socioeconomic determinants of hostseeking behaviors. The study aimed to determine the density of mosquito species and effect of some climatic parameter in Aminu Kano Teaching Hospital, Kano, Nigeria. 


\section{MATERIALS AND METHODS \\ Study Area}

The study was conducted at the College of Health Sciences Bayero University Kano, situated at Aminu Kano Teaching Hospital (AKTH). The hospital is located in Tarauni local Government area in the locality of UnguwaUku within the city of Kano. Geographically, AKTH lies between latitude 11 ${ }^{\circ} 57^{\prime}$ $31^{\circ} \mathrm{N}$ and longitude $8^{\circ} 32^{\prime} 39.4^{\circ} \mathrm{N}$ (Source?) and features a tropical savanna climate. Kano State has an average rainfall of about $980 \mathrm{~mm}$ of precipitation per year, the bulk of which falls between June and September. The climatic condition of the area is characterized by hot temperature but from December to February it is tropically cold (Barau, 2007). The hospital is traversed by River Kundum, a swamp and astagnant water pond. The hospital environment contains natural vegetation, and ornamental plants, this predisposes them to the influx of mosquito species and increases malaria active mosquito breeding sites (Barau, 2007).

\section{Ethical Clearance}

Ethical clearance was obtained from Aminu Kano Teaching Hospital ethical and research committee before the commencement of the study with reference number (AKTH/MAC/SUB/12A/P- 3/VI/2222).

\section{Mosquito collection}

The mosquitoes species were collected daily from the month of January to July, using the CDC light trap method. The light trap lamp was hung on a post, positioned at about 1.5 meters ( 6 feet) above the ground level, and a trap was switched on at $6 \mathrm{pm}$ and switched off at $6 \mathrm{am}$. Mosquito activities towards the lamp were monitored and observations was recorded, then at each hour the traps were inspected and mosquitoes were collected into clear label collection pots and kept in the cool box for transportation to the laboratory (Cook et al., 2007).

Climatic parameters such as temperature and relative humidity were recorded at every hour of the sampling period (Manger et al., 2014).

\section{Morphological Identification and Sorting}

Collected mosquitoes were sorted and identified to species level according to standard morphological keys by Gillies and
Coetzee (2013). Samples brought to the laboratory were sorted, non-mosquitoes were removed and each mosquito placed individually on a glass slide using forceps and placedunder a stereomicroscope and are identified using standard keys of Gillies and Coetzee (2013). The identification was done to species level. Morphological characteristics including the length of the palps concerning proboscis, the number of bands on both the palps and the proboscis, the antennae, wing spots (pale and dark areas), bands and speckles on the legs. These features were used in the identification of mosquito species that were caught in the study area. Sampled mosquitoes were classified as either culicineg, anopheline or others (Gillies and Coetzee, 2013).

\section{Statistical Analysis}

The results were presented as Tables, Bars or Line Graphs and using statistical package for social sciences (SPSS) version 20.0 (IBM Inc, Armonk, New York, USA) at 95\% confidence of interval.

\section{RESULTS}

A total of 26,652 mosquitoes were collected from January to July 2018, out of the 26,652, 17444 (65.46\%) were Culicine and 9208 (34.54\%) were Anopheline mosquitoes. The population of Anopheline mosquitoes increased in July to 2741 (29.76\%) followed by 2085 (22.64\%) in June but decreased in April and May 341(3.70\%) and $356 \quad(3.86 \%)$ respectively. The Culicine mosquito populations were observed to be higher in June and July 4062 (23.28\%) and 3720 (21.35\%) respectively (see Table 1).

Table 2 shows monthly abundance of mosquito species. Anopheles gambiae and Anopheles funetuspopulations increased in July to 1628 (29.01\%) and 812 (31.19\%) respectively while species of Culexquinquefasciatus were observed to be more abundant in June $4002(24.12 \%)$. The least abundance of the mosquito species was in April and May.

The highest abundance of mosquito population was found at a temperature range between $22.30-27.10^{\circ} \mathrm{C}$ and a relative humidity range between $68.60 \%-69.70 \%$. The population dropped at a temperature range between $32.40-33.56^{\circ} \mathrm{C}$ and a relative humidity range between $4.3 \%-6.2 \%$ (Table 3 ). 
Table 1 Distribution and Abundance of Monthly Collection of mosquito species

\begin{tabular}{lll}
\hline Months & $\begin{array}{l}\text { Culex } \\
\mathbf{n = 1 7 4 4 4}(\boldsymbol{\%})\end{array}$ & $\begin{array}{l}\text { Anopheles } \\
\mathbf{n = 9 2 0 8}(\boldsymbol{\%})\end{array}$ \\
\hline January & $3204(18.37)$ & $1025(11.13)$ \\
February & $2923(16.76)$ & $1754(19.05)$ \\
March & $2272(13.02)$ & $906(9.84)$ \\
April & $522(2.99)$ & $341(3.70)$ \\
May & $741(4.25)$ & $356(3.87)$ \\
June & $4062(23.29)$ & $2085(22.64)$ \\
July & $3720(21.33)$ & $2741(29.77)$ \\
Total & $\mathbf{1 7 4 4 4 ( 1 0 0 )}$ & $\mathbf{9 2 0 8}(\mathbf{1 0 0})$ \\
\hline
\end{tabular}

Table 2: Monthly Abundance and distribution of Mosquito Species

\begin{tabular}{|c|c|c|c|c|c|}
\hline \multirow[t]{2}{*}{ Months } & \multicolumn{3}{|c|}{ Anopheline species } & \multicolumn{2}{|c|}{ Culicine species } \\
\hline & $\begin{array}{l}\text { An. gambiae } \\
\mathrm{n}=5613(\%)\end{array}$ & $\begin{array}{c}\text { An. funestus } \\
\mathrm{n}=2603(\%)\end{array}$ & $\begin{array}{l}\text { Others } \\
\mathrm{n}=992(\%)\end{array}$ & $\begin{array}{l}\text { Culexquinquefasciatus } \\
\mathrm{n}=16508(\%)\end{array}$ & $\begin{array}{l}\text { Others } \\
\mathbf{n}=\mathbf{8 5 6}(\%)\end{array}$ \\
\hline February & 997 (17.76) & $584(22.43)$ & $173(17.43)$ & $2622(15.80)$ & $301(35.16)$ \\
\hline March & $558(9.94)$ & $280(10.75$ & $68(6.85)$ & $2202(13.27)$ & $70(8.17)$ \\
\hline April & $210(3.74)$ & $106(4.07)$ & $25(2.52)$ & $512(3.08)$ & $10(1.16)$ \\
\hline July & $1628(29.01)$ & $812(31.19)$ & $301(30.34)$ & $3520(21.22)$ & $200(23.36)$ \\
\hline Total & $5613(100)$ & $2603(100)$ & $992(100)$ & $16588(100)$ & $856(100)$ \\
\hline
\end{tabular}

Table 3: Effect of Temperature and Relative Humidity on Mosquito Species Distribution and Abundance

\begin{tabular}{|c|c|c|c|c|}
\hline Months & Temperature $\left({ }^{\circ} \mathrm{C}\right)$ & Relative Humidity (\%) & Culicine & Anopheline \\
\hline January & 22.60 & 17.85 & $3204(18.36)$ & $1025(11.13)$ \\
\hline February & 22.30 & 16.20 & $2923(16.75)$ & $1754(19.04)$ \\
\hline March & 22.30 & 17.40 & $2272(13.02)$ & $906(9.83)$ \\
\hline April & 33.56 & 4.3 & $522(2.99)$ & $341(3.70)$ \\
\hline May & 32.40 & 6.2 & $741(4.24)$ & $356(3.86)$ \\
\hline June & 27.10 & 69.70 & $4062(23.28)$ & $2085(22.64)$ \\
\hline \multirow[t]{2}{*}{ July } & 27.10 & 68.60 & $3720(21.32)$ & $2741(29.76)$ \\
\hline & & Total & $17444(100)$ & $9208(100)$ \\
\hline
\end{tabular}




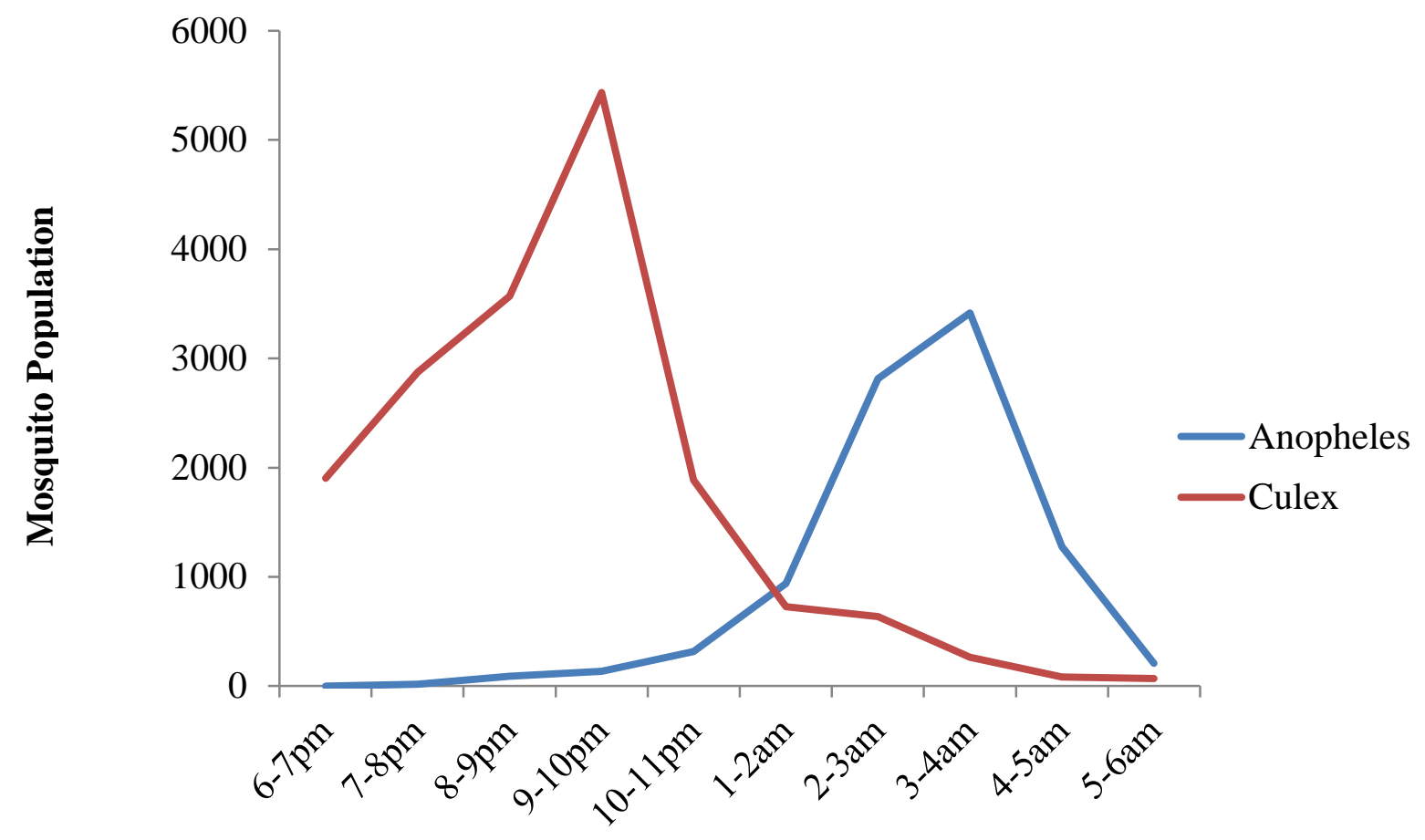

Figure 1: Periodic Variation in the Distribution of Mosquito Species

Figure 1 shows the periodic variation in the distribution of mosquito species. Culicine species were observed to have 2 peaks of abundance with the first peak at 9:00-10:00 pm and second peak at 10:00 - 11:00pm with a population of 3571 and5435 while Anopheline mosquito species were observed to attain their first peak at 2:00-3:00am with population of 2815 and second peak at 3:00-4:00am with population of 3416 .

\section{DISCUSSION}

The significant population of mosquitoes recorded in the study area may be attributed to the ecological features, climatic conditions, and activities of the residence which favor the rapid breeding of mosquitoes (Service, 1993). Braack et al. (2015) reported the increased tendency of mosquito populations may be due to changes caused by environment as aresult of shift in the behavior of mosquitoes, increase tendency to feed outdoor, bite earlier or late at night, and reduce anthrophagy in the presence of vector control measures (Braack et al., 2015). The result also showed that Culicine mosquitoeswere more abundant during the collection; this can be associated with their resting and feeding habits, presence of stagnant pond, high vegetation, ornamental plants, and nearness to flowing river as well as the method employed in their collection (Odetoyinbo, 1969; Owino et al., 2017). Culicinemosquitoesareknown to be fairly abundant with a wide geographical distribution in many parts of Africa including Nigeria, Zambia, South Africa, Kenya and Tanzania (Owino et al., 2017), adapting to almost every climatic condition. The outcomes of this study reported the high abundance of Culicine as a potential secondary vector of other infections (Msugh-Ter et al., 2017).
The result shows that there is a significant increase in Anophelinemosquitoes collected in June and July 2018. This may be a result of an increased in the rainfall which potentially increases breeding habitats of Anopheline mosquitoes. Anopheline mosquitoes in Africa typically breed in shallow water bodies, rice cultivation sites, and freshwater patches and increased in the flow of rivers (Lindsay et al., 1998). Previous studies showed that An. gambiae prefers more humid areas, freshwater body and Rice cultivation site for their breeding, hence the predominance of Anophelines(Lindsay et al., 1998). The significant decrease in An. funestus in January, February, March, April, and May (Table 2) may be due to decreased in sites which are characterized by high aquatic vegetation (Lindsay et al., 1998). The high density of An. gambiae may be explained by the anthropophilic behavior and adaptation to the human environment (Fonadel et al., 2013).

In this study it was found that mosquito species have their own specific time of abundance of which Culicine species were observed to have two peaks between 9:00 - 10:00 pm and secondly at 10:00 - 11:00 pm. This phenomenon can be attributed to their feeding behavior and gonotrophic cycle which coincide with human diurnal activities (Maliti et al., 2016). The 
use of long-lasting insecticide net (LLINs) prompted vectors to shift their biting time to when people are not protected, such as early in the evening and or outdoor. However, it is uncertain whether this behavioral shift is due to phenotypic plasticity and ecological changes within communities that favor more exophilic species or involve genetical factors within vector species to limit their contact with LLINs (Maliti et al., 2016).

The population of the Anopheles mosquitoes, attain peaks at 2:00-4:00 am, this may be associated with the endophilic feeding behavior of the mosquito species. Mosquito species abundance has been described to fluctuate with time and human activities, some exophilic species tend to be more abundant when human activity is more while the endophilic species become more inside human habitation (Gillies and Coetzee, 2013). Few studies have investigated the clock gene in An. gambiaesl and their association with diet activity such as blood-feeding (Bayoh et al., 2014). An. funestus were more likely to bite in the evening, hence the abundance of Anopheles in the late night. Generally, the mosquito was classified into the phenotype of "early" $7-10$ pm or "late" 4 7 am biting time and host-seeking indoor or outdoor (Braack et al., 2015).

The result shows that there is a direct relationship between mosquitoes with temperature. Mosquito is known to prefer an optimum temperature for breeding activities. The highest abundance of mosquito population was between $22.60-27.10^{\circ} \mathrm{C}$ with a significant noticeable decline in the population at a hightemperature range of about $32.40-33.56^{\circ} \mathrm{C}$. Local climatic parameters particularly temperature and relative humidity were found to play a vital role in the abundance of mosquito species in several studies (Ayanda, 2009; Beck-Johnson et al., 2013).

The adverse effect of low relative humidity on mosquito abundance has been reported in the early studies (Killen, 2013). In this study also the survival of mosquito was intimately associated with changes in relative humidity in the environment. This agreed with the Study of Ayanda (2009) that reported relative humidity as an important feature that causes the abundance of mosquito populations (Ayanda, 2009).

\section{CONCLUSION}

In this study, high collections of mosquitoes were shown to be obtained at optimum temperature and relative humidity. This indicated that the highest abundance of mosquitoes was dependent on the climatic parameters. The study also provided information on the mosquito species population at AKTH.

\section{REFERENCES}

Adeleke, M. A., Mafiana, C. F., Idowu, A. B., Sam Wobo, S. O. and Idowu, O. A. (2010). Population dynamics of indoor sample mosquitoes and their implication in disease transmission in Abeokuta Nigeria, Journal of Vector Borne Disease, 47:33 38.
Ayanda, O. I. (2009). Relative abundance of adult female Anopheles mosquitoes in UgahNassarawa State, Nigerian. Journal of Parasitology and Vector Biology, 1:005 - 008.

Ayanlade, A., Adeoye, N.O. and Babatimehin, O., (2013). Intraannual climate variability and malaria transmission in Nigeria. Bulletin of Geography. Socio-economic Series, 21: 7-19.

Barau, A. S. (2007). The great attraction of Kano research and Document Directorate Government House Kano.

Bayoh, M. N., Walker, E. D. and Kosgei, J. (2014). Persistently high estimates of late night, indoor exposure to malaria vectors despite high coverage of ITNs. Parasites and Vector, 7: 380393

Beck Johnson, L. M., Nelson, W. A., Paaijmans, K. P., Read, A. F., Thomas, M. B. and Bjornstad, O. N. (2013). The effects of temperature on Anopheles mosquito population dynamic and potential for malaria transmission. Public Library of Science ONE, 8(11):792 - 796 .

Braack, L., Hunt, R. and Koekemoer, L. L. (2015). Biting behaviour of African Malaria vectors, where do the main vector species bite in the human body. Parasites and Vector, 8:76-86.

Cook, S. M. Khan, Z. R. and Pickett, J. A. (2007). The use of push-pull strategies in integrated pest management. Annual Review ofEntomology, 52:375 - 400.

Fonadel, M., Muhiri, J. M., Muriu, M. S., Nzovu, J., Midega, J. T. and Mbogo, C. (2013). The role of Anopheles arabiensis and A. Coustani in indoor and outdoor malaria transmission in Taveta District Kenya. Parasites and vectors, 6:114 - 123.

Gillies, M. T. and Coetzee, M. (2013). A supplement to the Anopheline of Africa South of the Sahara (Afro-tropical Region). South African Institute of Medical Research,Pp 55.

Herekar F, Iftikhar S, Nazish A, Rehman S. (2020). Malaria and the climate in Karachi: An eight year review. Pakistan Journal of Medical Sciences, 36(1):33 - 37.

Jiang, S., Xiao, B. and Wu, C. (2007). The result of analysis and surveillance on the relevant factor affecting malaria Prevalence before three George Dam Construction. Journal of Tropical Disease and Parasitology,5:73 - 78 .

Killen, G. F. (2013). A second chance to tackle African malaria vector mosquitoes that avoid houses and don't take drugs. American Journal of Tropical Medical hygiene, 88(5):809816. 
Lima, J. B., Roja-Freites, M. W., Rodovalho, C. M., santos, F. and lourenco-de-oliveira, R. (2014). Is there an efficient trap or collection method for sampling Anopheles and other malaria vectors that can describe the essential parameters affecting transmission dynamics as effective as human landing catching a review? Member Institute of Oswald Cruz, 109: 685 - 705.

Limitation of CDC miniature light trap for measuring biting density of African malaria vector population a pooled analysis of thirteen comparisons with human landing catch. Biomedical and Clinical Malaria Journal, 14:247-260.

Lindsay, S. W., Parson, L. and Thomas, C. J. (1998). Mapping the ranges and relative abundance of two principal African Malaria vector, An. gambiaessand An. arabiensis using climate data. Proceedings of the Royal Society of London, 965:847 854.

Maliti, D. V., Marsden, C.D. and Main, B. J. (2016). Investigating associations between biting time in the malaria vector Aedesaegyptipattern and single nucleotide polymorphism in circadian clock genes: support for sub structure among Aedesaegyptiin the Kilombero Valley of Tanzania. Parasite Vector, 9:109-124.

Manyi, M. M., Akaahan, J. T., Azua, E.T. (2015). Relationship between Weather Parameters and Female Mosquitoes' Abundance and Distribution in Makurdi, a Mosquito Infested Area in North Central Nigeria. International Journal of Sciences, 4(6):44 - 54.

Menger, D. J. Van, I. and Takken, W. (2014). Assessing the efficacy of candidate mosquito repellent against the background of an attractive source that mimics a human host. Medical andVeterinary Entomology, 28:407 - 413.
MsughTer, M. M., Aker, P. and Dechi, A. A. (2017). Anopheles andCulex mosquito species Diversity and its Epidemiological Implication in the Makurdi Area of Benue State North Central Nigeria. Annals of Experimental Biology,5(1):9 - 13.

Odetoyinbo, J. A. (1969). Preliminary investigation on the use of light trap for sampling malaria vector in Gambia, Bulleting of World Health Organization, 40(1): 547 - 560.

Olivier, J. T. B., Bernadette, J. H., John, E. G., Nabie, B., Aklilu, S., Chadwick, H. S., Nicodem, G., Diadier, A. D., Salim, A., Thomas, A. S. and Gerry, F. K. (2015). Application of the

Owino, E. A., Garba, L. C., Oyieko, F. A. Mwansat, G. S., Houmson, R. S. Darda, F. (2017). Species Diversity and Relative Abundance of Anopheles vector of malaria on the highland of Mambilla Plateau Taraba Northeast Nigeria. Journal of Biotechnology and Bioengineering, 1:37 - 42.

Service, M. W (1993). Mosquitoes Ecology Field Sampling Methods $2^{\text {nd }}$ Edition. London Elsevier Applied Science publishing Ltd. Pp. 988.

WHO (2017). A framework for Malaria Elimination, Global Malaria Programme. Geneva: World Health Organization; 2017, Retrieved on $24^{\text {th }}$ September, 2019.

(C)2020 This is an Open Access article distributed under the terms of the Creative Commons Attribution 4.0 International license viewed via https://creativecommons.org/licenses/by/4.0/ which permits unrestricted use, distribution, and reproduction in any medium, provided the original work is cited appropriately. 